\title{
Diffusion of Protein Molecules through Microporous Nanofibrous Polyacrylonitrile Membranes
}

Cunyi Zhao ${ }^{1}$, Yang $\mathrm{Si}^{1 \#}$, Shenghan Zhu ${ }^{1}$, Kevin Bradley ${ }^{1}$, Ameer Y Taha ${ }^{2}$, Tingrui Pan $^{3}$, Gang Sun ${ }^{1 *}$

${ }^{1}$ Department of Biological and Agricultural Engineering, University of California, Davis, CA 95616, USA.

2 Department of Food Science and Technology, University of California, Davis, CA 95616, USA

${ }^{3}$ Department of Biomedical Engineering, University of California, Davis, CA 95616, USA \#Current address: College of Textiles, Donghua University, Shanghai, China ${ }^{*}$ Corresponding author: E-mail: gysun@ucdavis.edu; Fax: +530-752-7584; Tel: +530752-0840 

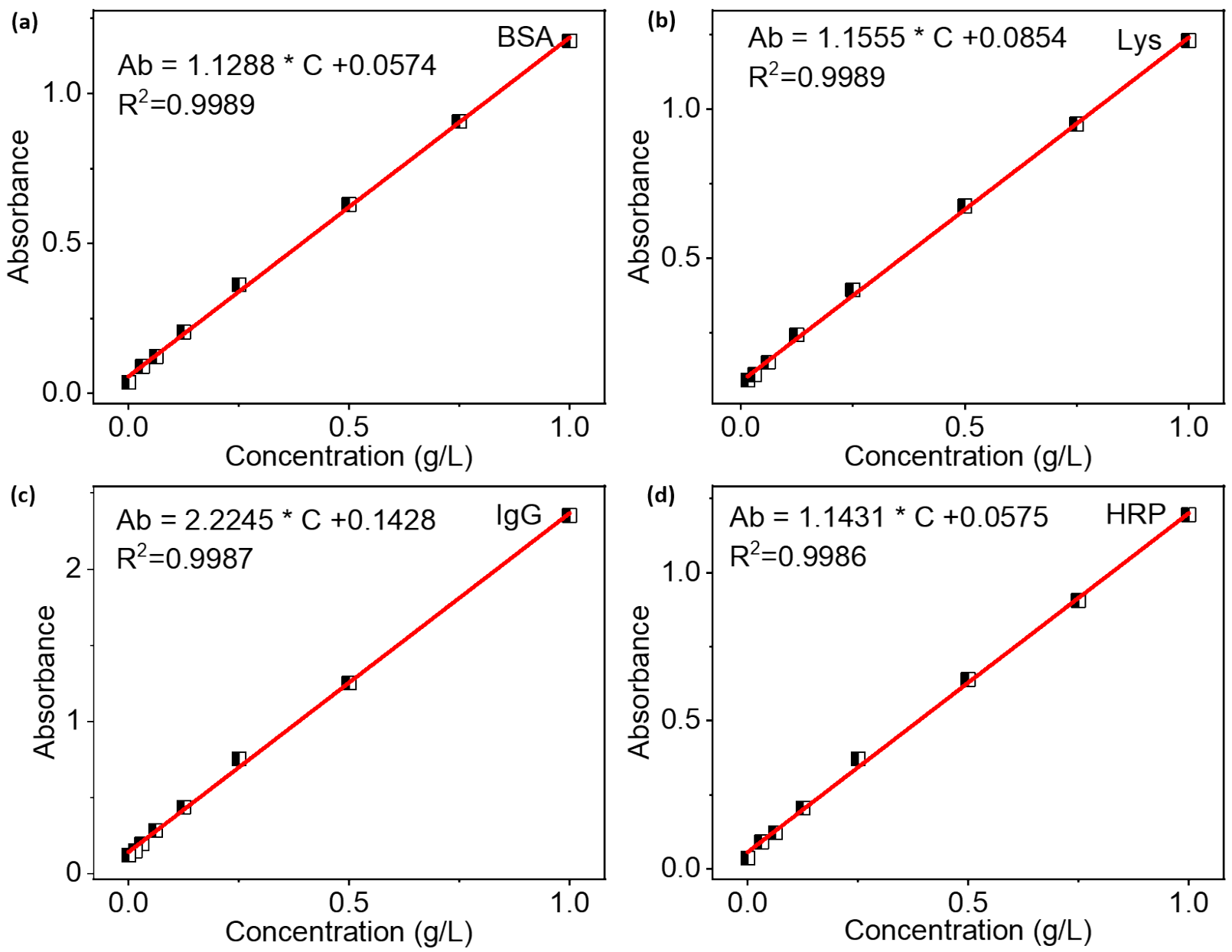

Figure S1, The calibration curves of UV-vis absorbance versus concentration of (a) BSA, (b) Lysozyme, (c) IgG, and (d) HRP 


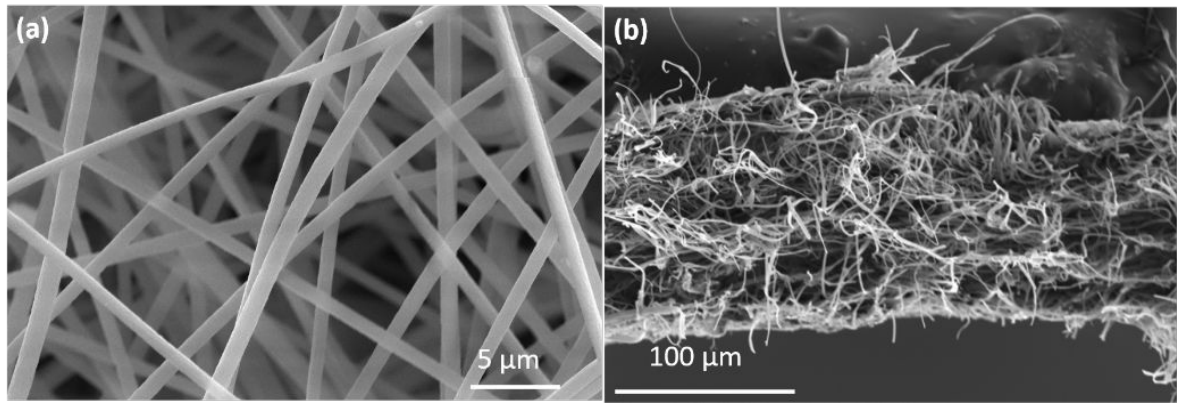

(c)

Figure S2, The SEM images of (a) top view and (b) cross-section of electrospun nanofibrous membrane; (c) a scheme of electrospun nanofibrous membrane 
Table S1. The fiber volume fractions and adsorption constants of prepared membranes

\begin{tabular}{rcccc}
\hline & Fiber diameter $(\mathrm{nm})$ & Pore size $(\mu \mathrm{m})$ & Fiber volume fraction $(\%)^{\mathrm{a}}$ & $\mathrm{K}$ \\
\hline $6 \mathrm{wt} \%$ & 175.64 & 0.380 & 8.62 & 35.84 \\
$7 \mathrm{wt} \%$ & 273.53 & 0.400 & 7.70 & 41.93 \\
$8 \mathrm{wt} \%$ & 351.62 & 0.586 & 7.60 & 46.12 \\
$10 \mathrm{wt} \%$ & 522.00 & 2.086 & 7.50 & 47.96 \\
$12 \mathrm{wt} \%$ & 782.18 & 2.522 & 7.31 & 46.11 \\
$30 \% \mathrm{RH}$ & 315.84 & 1.590 & 8.40 & 38.97 \\
$40 \% \mathrm{RH}$ & 438.10 & 1.239 & 8.28 & 40.41 \\
$50 \% \mathrm{RH}$ & 522.00 & 2.086 & 7.50 & 47.90 \\
$60 \% \mathrm{RH}$ & 531.60 & 2.211 & 7.49 & 45.70 \\
$70 \% \mathrm{RH}$ & 634.97 & 8.836 & 7.90 & 38.12 \\
\hline
\end{tabular}

aFiber volume fraction: $\varphi=\frac{m / d_{p}}{V_{t}} * 100 \%$ where $\varphi$ is fiber volume fraction, $\mathrm{m}$ is the mass of membrane, $d_{p}$ is the density of PAN polymer, and $V_{t}$ is the total volume. 